\title{
DESIGN E COMUNICACÃO VISUAL: uma aproximação entre Panofsky e métodos de projeto em design'
}

\author{
Rubia Ferreira Melo \\ Alessandra Carvalho Van Der Ley Freitas Lins \\ Maria Eduarda Ramos Alves Soares \\ Danielly Amatte Lopes
}

\begin{abstract}
Resumo: A linguagem visual é uma das formas de comunicação mais usadas na contemporaneidade. Investigar o processo de formação de significado a partir dessas composições gráficas tem sido objeto de estudo das mais diversas áreas ao longo do tempo, inclusive contribuindo para o desenvolvimento de um design cada vez mais eficiente e assertivo. Dentro do campo da linguagem visual e do design gráfico, entendemos que a imagem é um dos componentes fundamentais do trabalho do designer da informação e como tal, precisa ser cuidadosamente analisada e compreendida pelo projetista. Sendo assim, buscamos no presente trabalho, estabelecer conexões entre os conceitos de "iconografia" e "iconologia" propostos pelo historiador da arte Erwin Panofsky (2011) em sua obra Significado nas Artes Visuais e um possível uso desses conceitos junto ao design.
\end{abstract}

Palavras-chave: design, método, iconografia e iconologia

\section{INTRODUÇÃO}

A linguagem visual é uma forma de comunicação muito importante para o ser humano. Através dela somos capazes de sintetizar informações e assim, receber e transmitir mensagens em diversos tipos de suporte, podendo dessa maneira atingir os mais diversos públicos e disseminar conteúdos de forma mais rápida e abrangente. Contemporaneamente, podemos perceber que somos colocados em contato com uma quantidade muito grande de imagens e construções gráficas que ora esperam do espectador uma visão passiva, que assimile um conteúdo, ora pretende que esse espectador reaja e assim, interaja com a peça gráfica visualizada.

Se por um lado o receptor precisou se adequar, por outro lado, aquele que emite a mensagem precisa lidar com destinatários que também buscam agilidade e qualidade nessas novas informações e com a segmentação desses públicos diversos a quem a mensagem da composição pretende atingir. Ao resgatarmos Twemlow (2007), quando a mesma diz que 'Os princípios fundamentais do design de informação é construir um corpo de dados complexos compreensíveis e imediatamente acessíveis a suas audiências. ' (TWEMLOW: 2007, p.106), vemos que o designer pode assumir, nesse fluxo de produções, o papel de gestor dessas variáveis interpretativas presentes nas imagens.

1 Artigo apresentado no $8^{\circ}$ Congresso Nacional de Iniciação Científica em Design de Informação (CONGIC) 
Neste trabalho resgatamos parte do trabalho de Panofsky (2001) e traçamos algumas considerações sobre uma aproximação entre o design e os conceitos de "iconografia" e "iconologia" do autor supracitado. Para subsidiarmos essas considerações, trazemos agora um breve exame sobre a relação do design com a cultura e a percepção.

\section{DESIGN, CULTURA E PERCEPC̣ÃO}

O homem desde sua origem interage com a natureza, e este por sua vez como ser biologicamente adaptável, utiliza dos elementos que lhes são promovidos, transformando-os e incorporando-os ao seu meio de viver. Forma-se uma teia de costumes e acepções a que podemos chamar de cultura. Diversos conceitos e definições foram desenvolvidos por pesquisadores referentes aotermo. Porém, as diversas visões sobre cultura, associam-se quando consideram que a mesma compreende tanto os elementos materiais quanto os imateriais. Do ponto de vista de Denis (1998) o termo de cultura material é referente ao que se é produzido pela sociedade possibilitando 'uma maneira de entender melhor os artefatos que produzimos e consumimos, bem como a maneira com que estes se encaixam em sistemas simbólicos e ideológicos mais amplos' (DENIS, 1998, p.19-20).

O estudo de uma cultura não se resume ao que se foi produzido, ou seja, os materiais em sua forma concreta, mas tudo o que subsidiou tanto na síntese feita a partir de vários elementos quanto na origem da criação do material produzido. Desse ponto, o design sendo um veículo de comunicação, projeta em todo um contexto, os elementos representativos de uma cultura. Segundo Denis (1998) o design visa 'a objetivação no seu sentido estrito, ou seja, dar existência concreta e autônoma a ideias abstratas e subjetivas' (DENIS, 1998, p.19). Dessa forma, o designer surge como sujeito e objeto que comunicará o que o cliente e o usuário necessitam. Um design gráfico por sua vez, buscará por um contexto simbólico através de outras fontes de análise para reforçar os simbolismos que deseja passar.

Ou seja, o designer desempenha um papel de mediador entre o objeto e o usuário e precisa compreender as relações simbólicas contidas ali. Assim, após essa relação de design-cultura-percepção, observa-se que algumas áreas se dedicam a examinar os aspectos subjetivos e outras tentam tornar o subjetivo, objetivo e que Panofsky, ao tentar compreender o significado nas artes visuais, proporciona a partir de sua obra, uma possibilidade de abordagem.

\section{ICONOGRAFIA E ICONOLOGIA}

Trazendo do campo de estudos das artes visuais, temos a construção de um método para enfrentar a questão da atribuição de significado nesse campo construída por Erwin Panofsky em meados do século XX. Panofsky foi um historiador da arte que utilizou em sua obra,Significado nas Artes Visuais, um método de análise de imagens, mais especificamente das obras de artes, onde buscava compreender como eram atribuídos significados as formas, cores, texturas presentes nas obras. Ou seja, como o visual se tornava simbólico, se tornando portador de um significado.

Para o autor "perceber a relação de significação é separar a ideia do conceito a ser expresso, dos meios de expressão. E perceber a relação de construção, é separar a ideia da função a ser cumprida dos meios de cumpri-la" (PANOFSKY, 2001, p. 24).Seguindo esse pensamento o autor nos apresenta dois conceitos que, quando apropriados pelo design, nos permitem replicar sua contribuição feita no campo das artes visuais, para o campo do design, sobretudo do design da informação. São eles os conceitos de "iconografia" e 
"iconologia".

\subsection{As Diferenças entre Iconografia e Iconologia}

Para destrinchar o processo de formação de significação em uma obra de arte, Panofsky foi estruturando um método onde tenta compreender o processo cognitivo percorrido pelo observador, para que entenda a mensagem contida na obra e expressa apenas pelos elementos visuais dessa obra. Seu objetivo era tentar entender como linhas, cores e texturas eram reconhecidas de maneira fatual e como, partindo delas, entendia-se isso ou aquilo da obra em questão.

O autor esquematiza sua análise em três níveis. O primeiro, que chama préiconográfico, estaria na esfera do reconhecimento. O observador reconhece naquele conjunto de elementos compositivos um elemento algo do mundo natural e associa a ele uma expressividade, também reconhecida por sua experiência. Esse primeiro nível, que o autor chama de natural, está intimamente ligado com a percepção dos elementos compositivos e a vinculação desse conjunto de elementos com algo pertencente ao mundo cotidiano do observado

Continuando na busca pela compreensão da obra e seus significados seríamos levados a um segundo nível. A iconografia nasce quando superamos a significação natural e adicionamos àquelas representações, alegorias e histórias que mudam esse significado natural, agregando a ele aspectos que são específicos de uma cultura, de um recorte temporal onde o observador está inscrito. O autor identifica ainda um nível mais profundo de significação, onde o reside o que ele chama de conteúdo ou significado intrínseco.

Nesse terceiro nível a expectativa é de aprofundar mais ainda o reconhecimento de traços culturais, indo para além da análise promovida pela iconografia, chegando a uma síntese dos conteúdos intrínsecos já examinados. Segundo Panoffky (2011)

Iconologia, portanto, é um método de interpretação que advém da síntese mais que da análise. E assim como a exata identificação dos motivos é o requisito básico de uma correta análise iconográfica, também a exata análise das imagens, estórias e alegorias é o requisito essencial para uma correta interpretação iconológica (Panofsky: 2001, p.5051).

Reforçamos que toda essa construção se opera no observador, no sujeito "exposto" ao conjunto compositivo. É ele o usuário do sistema, capaz de atribuir certo significado, um significado que está intimamente ligado ao seu repertório, sua bagagem cultural e suas possibilidades perceptivas.

Também podemos concluir que o método postulado por Panofsky, em uma estrutura terciária que poderíamos ver como próxima ao que a semiótica propõe, prevê que para a apreensão do significado de uma obra de arte, é preciso um processo construtivo, onde um nível estrutura a compreensão de maneira a permitir que o próximo nível avance nesse exercício, como mostra o esquema a seguir. 
Figura 1: Processo de formação de significação segundo Panofsky. Fonte: autoral.

METODOLOGIA

PANOFSKY (2011)

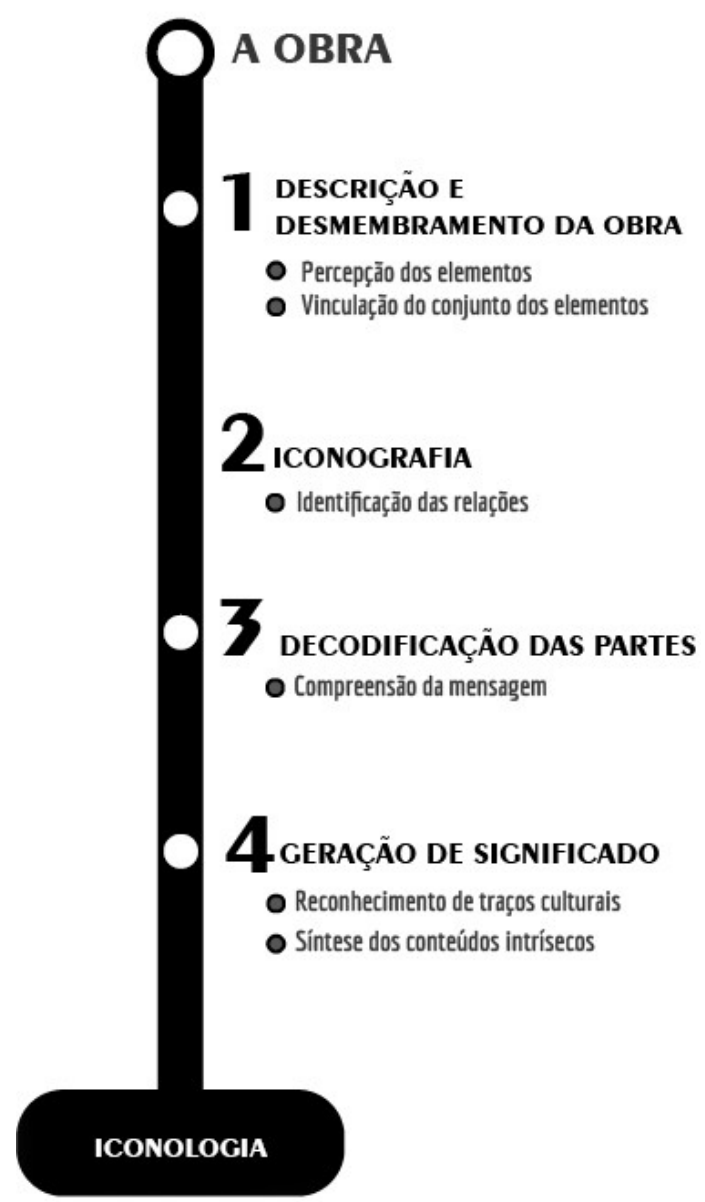

A formação dessa teia interpretativa não é muito distante do que temos no design. Assim como o observador da obra de arte é quem possui os meios para interpretar a obra, nosso público-alvo em um projeto é quem detém o repertório necessário para captar aquilo que foi proposto pelo sistema projetado. 0 que é preciso aqui é inverter o processo para nos aproximarmos de um uso desses conceitos e métodos advindos do campo da história da arte no campo do design.

\section{METODOLOGIA DE PROJETO EM DESIGN: APROXIMAÇÕES ICONOGRÁFICAS E ICONOLÓ- GICAS}

Entendendo método de design como um conjunto de procedimentos organizados, que buscam atingir um objetivo de projeto, vemos que é possível identificar diferentes propostas de organização acerca do processo projetual. Ao longo das últimas décadas, sobretudo a partir dos anos 1960, segundo Bonsiepe (2012) as atenções voltaram-se à metodologia projetual, culminando na sua academização e numa institucionalização dela enquanto disciplina nos cursos de design. Sobre esse processo o autor afirma que:

\footnotetext{
As reflexões acerca do processo projetual constituem uma operação estruturalista que visa montar o esqueleto da atividade projetual. Em termos gerais, trata-se de uma construção estruturalista, conjugando-se componentes analíticos com os componentes normativos. Partem da hipótese de que a atividade projetual de diversas disciplinas possui uma estrutura em comum, independente do conteúdo das tarefas projetuais (Bonsiepe:2012. p.92)
}

Em alguns casos temos métodos específicos, diretamente ligados ao objeto a ser 
gerado (Seragini no design de embalagens, Péon para sistemas de Identidade Visual, Löbach para projetos de produto etc.) No geral, embora se organizem de forma distintas, é possível identificarmos nas propostas metodológicas adotadas em projetos de design uma organização composta por cinco macrofases, via de regra. 0 usual é que essas metodologias se organizem em torno de (a) diagnosticar a necessidade do projeto, (b) analisar os dados obtidos (c) gerar alternativas (d) avaliar as soluções geradas e por fim (e) detalhar a solução final.

$\mathrm{Na}$ tentativa de ilustrar como as construções de Panofsky poderiam ser agregadas, descreveremos a seguir três métodos de projeto em design, fazendo um breve relato dos seus processos e identificando em que fase desse processo podemos vincular a construção de significados a partir de composições gráficas e os usuários propostos para o projeto. Examinaremos agora os métodos de Peón, Löbach e Bonsiepe.

\subsection{Maria Luísa Peón}

Péon (2013) indica que a identidade visual é um conjunto de elementos gráficos utilizados para representar determinada empresa. A fim de facilitar o processo de criação de uma identidade visual a autora identifica três grandes fases: problematização, concepção e especificação.

A problematização é a etapa que identifica requisitos e restrições do projeto. Dentre as etapas temos o Briefing e a determinação do Perfil de cliente e do usuário. Logo após se definirá uma contextualização simbólica, nessa etapa o designer deverá definir conceitos que valorizem a empresa junto a seu público, essa se mostra uma fase sensível pois muitos desses conceitos são códigos subjetivos, entendidos apenas naquele universo.

A próxima macro fase é a Concepção fase mais criativa do processo. Nela serão geradas alternativas para se selecionar a que melhor se aplique aos requisitos apresentados. Essa etapa do projeto irá utilizar toda a pesquisa que foi feita na problematização, transformando seus significados em elementos que possam diferenciar e atingir seu público. A primeira etapa dessa grande fase se define na geração de alternativas, onde o designer irá criar alternativas que atendam a proposta desenvolvida na problematização e que atenda aos requisitos apresentados no briefing. Após as fases de geração será feita a seleção da alternativa e definição do partido que atenda melhor todos estes requisitos, nessa fase irá se avaliar cada uma delas e depois fazer as escolhas finais as agrupando de acordo com os conceitos e elementos gráficos que as une. Logo após na solução preliminar deverá se gerar uma alternativa que passará pelas fases de avaliações. A partir dessa parte serão geradas soluções para os requisitos e problemas determinados, bem como as aplicações necessárias para aquela identidade.

Especificação: a fase final do projeto é a especificação, esta será a que irá garantir que o sistema será aplicado corretamente, o detalhamento e definição deverão ser feitos pelo designer. Na figura a seguir é possível ver o esquema ilustrado do método descrito. 
Figura 2: Metodologia de Maria Luísa Peón. Fonte: autoral baseado em Peón (2009).

\section{METODOLOGIA \\ MARIA LUÍSA PEÓN (2012)}

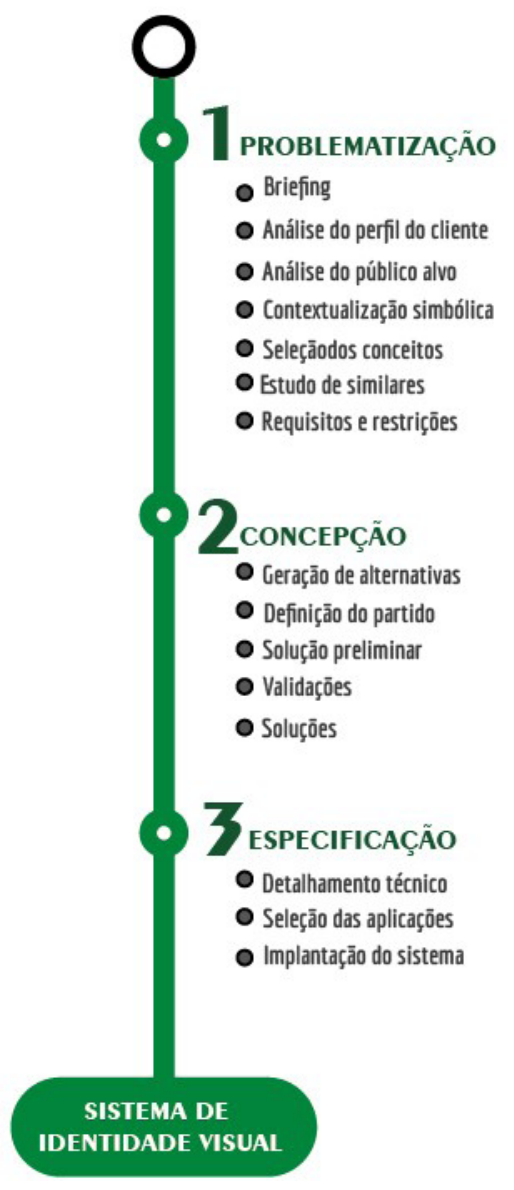

\subsection{Bernd Löbach}

Em sua obra ‘Design Industrial', Löbach aborda aspectos estéticos e subjetivos do design onde a metodologia elaborada por ele pode ser utilizada para diferentes tipos de projeto, mas é comumente utilizada para projetos voltados à indústria. Segundo LÖBACH (2001) o processo de design pode se desenvolver de forma extremamente complexa embora as fases do projeto nunca sejam exatamente separáveis no caso real, elas se entrelaçam umas às outras, com avanços e retrocessos.

Na sua metodologia, Löbach prevê quatro grandes etapas ou macro fases, e cada uma delas possui suas micro etapas, sendo que os métodos adotados para a solução dessas micro etapas são chamados pelo autor de processo de design. Lobach principia pelo que chama de Fase de preparação, na qual temos a análise do problema, depois a coleta de informações e posteriormente uma análise dessas informações coletadas. Como processo de design para essa etapa e suas micro etapas, o autor sugere a análise da necessidade, análise da relação social, análise da relação com ambiente, desenvolvimento histórico, análise do mercado, análise da função, análise estrutural, análise da configuração, análise de materiais e processos de fabricação, patentes, legislação e normas e análise de sistema de produtos.

A segunda macro fase proposta pelo autor é a Fase de geração. Nela, para encontrar as soluções para o problema serão geradas as alternativas. Feito isso, passasse para a próxima macro fase, a de avaliação. Nessa fase serão avaliadas as alternativas geradas pela fase anterior, as alternativas passarão por um processo de seleção e avaliação 
novamente. Os processos de design dessa etapa são: escolha da melhor solução e incorporação das características ao novo produto.

Chegamos então a quarta e última fase propostas por Löbach: a Fase de realização. Com as alternativas selecionadas e refinadas, a solução para o problema é realizada e acontece uma nova avaliação da solução alcançada. O autor lista os seguintes processos de design como pertencentes a essa macro fase: projeto mecânico, projeto estrutural, configuração dos detalhes, desenvolvimento de modelos, desenhos técnicos e de representação, documentação do projeto e relatórios.

Para um melhor entendimento de como essas fases e suas macro e micro etapas estão distribuídas ao longo do projeto, a imagem a seguir exemplifica essas relações.

Figura 3: Metodologia de Bernd Löbach. Fonte: autoral baseada em Löbach (2001).

\section{METODOLOGIA \\ BERND LÖBACH (2001)}

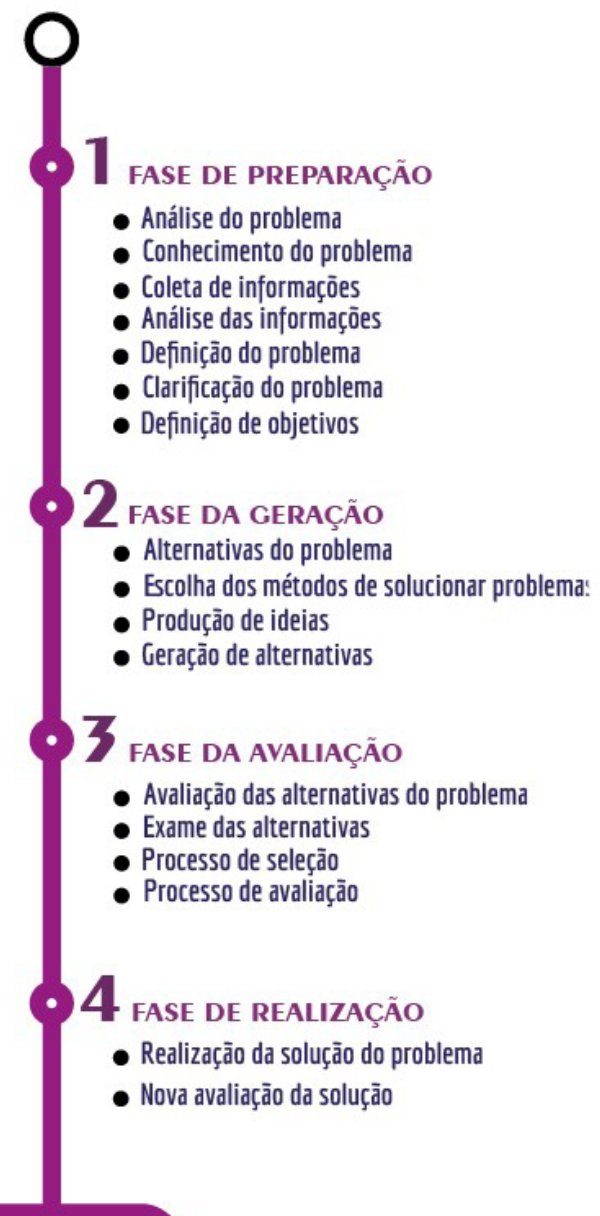

\section{PRODUTO}

\subsection{Gui Bonsiepe}

No campo do design, Bonsiepe (1983) desenvolveu uma metodologia direcionada para o processo projetual de produtos, apresentando técnicas e métodos a partir de projetos experimentais. As macro fases propostas por Bonsiepe são organizadas em cinco etapas, correspondendo:

1. Problematização: esta etapa representa a introdução ao projeto, onde serão traçadas as metas gerais, apresentando as influências e os agentes dos problemas, bem como o que deve ser melhorado. Dentro desta etapa, o público- alvo já é definido. 
2. Análises: para Bonsiepe esta etapa consiste em analisar as características dos produtos e os processos existentes, interpretando as informações que podem ser relevantes.

3. Definição do problema: ao chegar nesta fase, o problema é sintetizado, para serem hierarquizados e assim definidos os requisitos e parâmetros.

4. Anteprojeto: esta é a etapa que serão geradas as alternativas para solução do problema, através de técnicas que auxiliam na produção de ideias.

5. Projeto: com a alternativa escolhida, serão realizados os detalhamentos do projeto.

Para uma fácil compreensão da organização das macro fases e micro etapas desenvolvidas pelo autor, temos na a figura 4 abaixo

Figura 4: Metodologia de Gui Bonsiepe. Fonte: autoral baseada em Bonsiepe (2012).

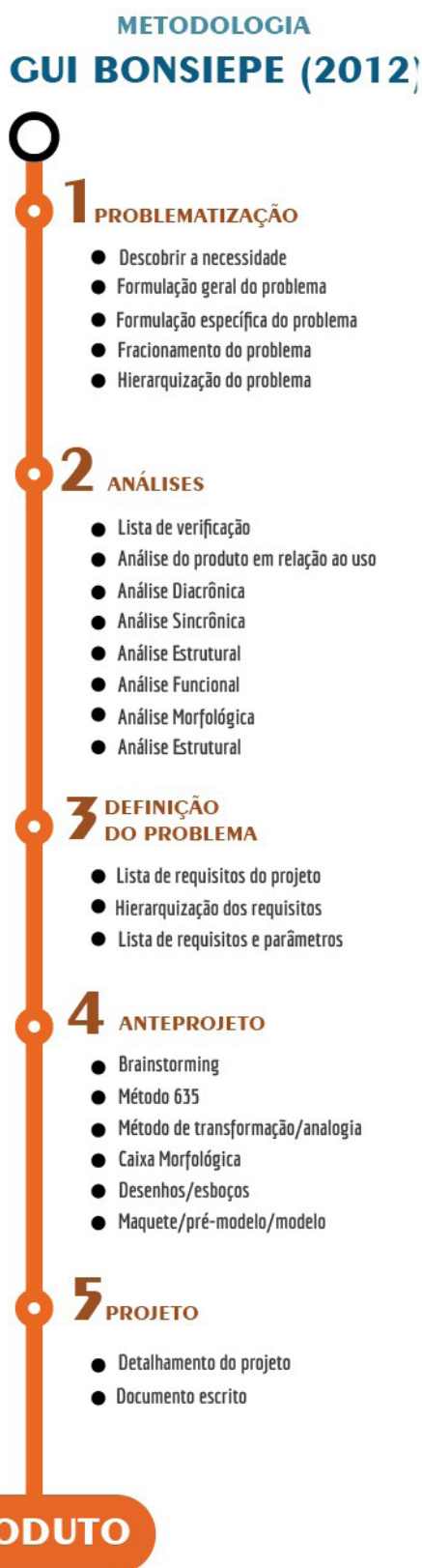

\section{CONSIDERACִÕES FINAIS: INTERSECC̣̃̃ES ENTRE METODOLOGIAS DE DESIGN E A VISÃO DE PANOFSKY}

Nas metodologias de design, o designer se propõe a conhecer o problema recolhendo informações úteis sobre os fatores e influências, e é nessa pesquisa que o público-alvo 
se encontra. Colocar o usuário como foco do projeto, permite criar uma relação de boa usabilidade entre o consumidor e o produto. Para Rubin (1994) o Design Centrado no Usuário (DCU) é uma filosofia que coloca o usuário no centro do desenvolvimento do projeto, levando em consideração as necessidades, características e desejos dos consumidores, utilizando assim, de métodos e técnicas que aproximem os mesmo para o processo de design. Para isso é necessário que o designer tenha em mente a necessidade de conhecer a singularidade do público, levando em conta a diferenças sociais e culturais, permitindo que a margem de erro na criação de um produto seja menor, e garantindo que se crie obras que tenham um apelo maior ao usuário e fazendo ele se sentir representado por aquilo.

É desse processo de compreensão do usuário que tanto o designer, quanto Panofsky se interseccionam. O primeiro parte do significado para identificar o repertório do usuário e construir a peça, onde se tem como objetivo atingir um sentido específico. Já o segundo, inicia sua busca na obra, buscando decifrar os elementos que permitem a ela ter esse ou aquele significado. Percebemos que ambos os processos dependem intimamente do usuário e do sistema de significações desse usuário e que, como podemos ver na figura 5 a seguir, o exame desse interlocutor está presente nas três metodologias aqui descritas.

Figura 5: Esquema Gráfico criado a partir das fases das Metodologias Projetuais de Péon (2013), Lobach (2001) e Bonsiepe (2012), localizando o usuário nesse percurso, também localizando o usuário em Panofsky (2001). Fonte autoral.

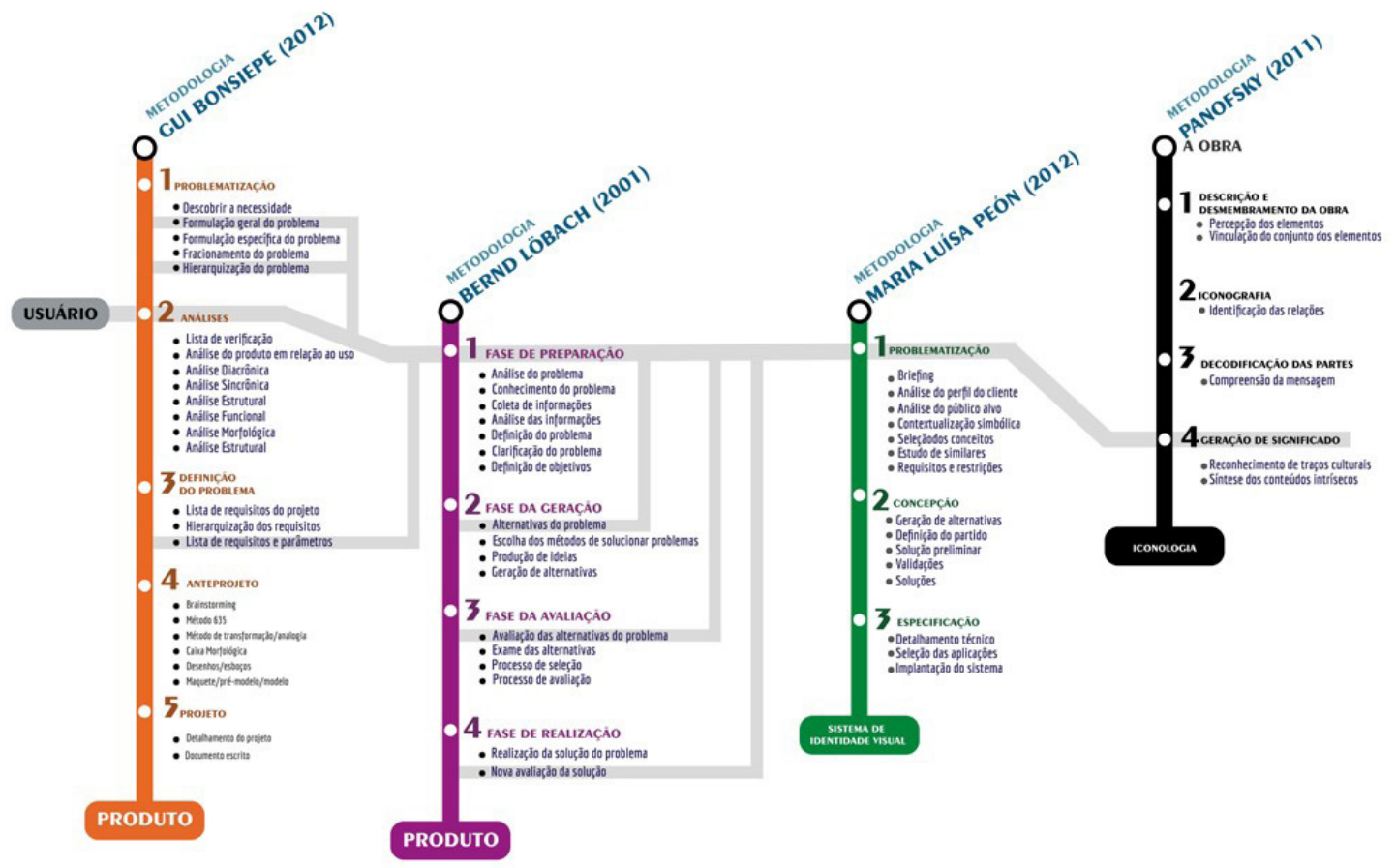

Ao examinar a imagem acima, podemos identificar que as propostas metodológicas adotadas pelo design lidam com o usuário e seu repertório, mesmo que em momentos diferentes, para assim assegurar o uso dos elementos simbólicos adequados para aquele público. Péon (2012) localiza o público alvo já na problematização, quando é feita sua 'contextualização simbólica', etapa que pode ser conectada a pesquisa iconográfica e iconológica de Panosfky (2011), que considera o aspecto cultural e o significado intrínseco na catalogação de elementos. O diferencial é que, enquanto Panofsky busca esses conceitos para entender uma obra, o designer o faz para criar uma identidade ou produto.

Löbach (2001) e Bonsiepe (2012), por sua vez, procuram entender e identificar o problema dos usuários e, a partir daí gerar uma solução adequada, de maneira que o usuário tenha uma boa experiência com o produto. Assim como Panofsky construiu 
sua metodologia para identificar os processos por trás dos símbolos e descobrir os significados identificados pelo usuário, nas metodologias de design conhecer o usuário torna-se essencial para atender suas expectativas sobre um determinado produto.

Vemos que designer precisa estar atento ao público-alvo, pois é do repertório do público que depende a apreensão do significado pretendido e, embora Panofsky parta da obra em si, entender esse processo de atribuição de sentido agrega ao trabalho do designer novas possibilidades de abordagem e até mesmo uma nova visão sobre antigas ferramentas, evidenciando como a cultura e a percepção são importantes no processo de significação das imagens, seja nas artes, seja no design.

\section{REFERENNCIAS} 1997.

ANDERSON, P.1997. A civilização e seus significados. Praga. Rio de Janeiro, no. 2, junho,

BONSIEPE, G. A Tecnologia da Tecnologia. São Paulo: Ed. Blüicher, 1983.

BONSIEPE, G. Design como prática de projeto. São Paulo: Blucher, 2012.

DENIS, R. C. Design, cultura material e o fetichismo dos objetos. In: Revista Arcos. Design, cultura material e visualidade, Rio de Janeiro, v. 1, número único, p. 1439, out. 1998.

GEERTZ, C. A interpretação das culturas. Rio de Janeiro: LTC, 1989. 1997.

HATCH, M. J. - Organization theory: modern symbolic and postmodern perspectives,

LÖBACH, B. Design Industrial: base para configuração de produtos industriais. São Paulo: Ed.Blücher, 2001.

ONO, M. M. Design, Cultura e Identidade, no contexto da globalização. Revista Design em Foco [online] 2004, I (julho-dezembro): Disponível em: http://www.redalyc.org/ articulo.oa?id=66110107. Acessado em: 05 de junho de 2017.

PANOFSKY, E. Significado nas artes visuais. 3o ed. São Paulo: Perspectiva, 2011.

PEÓN, Maria Luísa. Sistemas de identidade visual. Teresópolis: 2AB Editora, 2013.

TWEMLOW, A. Para que serve o design gráfico? São Paulo: Gustavo Gili, 2007, p. 106.

VILLAS-BOAS, André. Identidade e cultura: design gráfico. 2o ed. Rio de Janeiro: 2AB Editora, 2009.

Sobre as autoras:

Rubia Ferreira Melo (graduanda), UFAL <rubiamell@gmail.com>

Alessandra Carvalho Van Der Ley Freitas Lins (graduanda), UFAL <alessandracvanderlry国gmail.com>

Maria Eduarda Ramos Alves Soares (graduanda), UFAL <dudaramos.a国hotmail.com>

Danielly Amatte Lopes (doutora), UFAL <danielly.lopes@fau.ufal.br> 